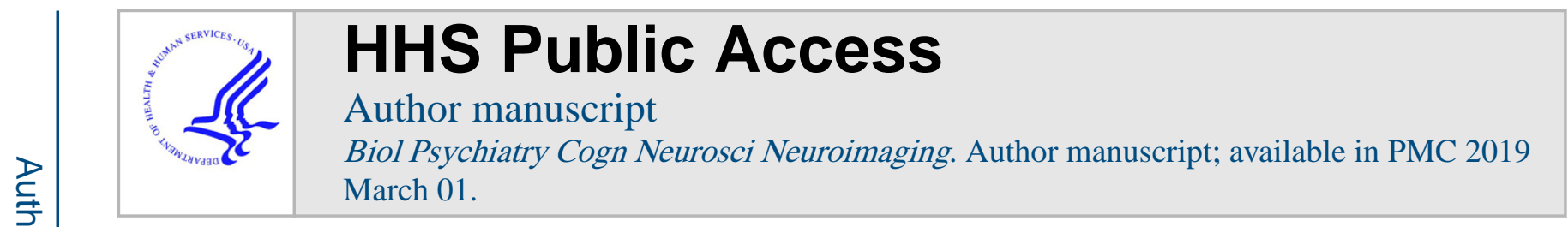

Published in final edited form as:

Biol Psychiatry Cogn Neurosci Neuroimaging. 2018 March ; 3(3): 231-238. doi:10.1016/j.bpsc. 2017.02.005.

\title{
Mnemonic Discrimination Deficits in First Episode Psychosis and a Ketamine Model Suggests Dentate Gyrus Pathology Linked to NMDA-Receptor Hypofunction
}

\author{
Nina Vanessa Kraguljac ${ }^{1}$, Matthew Carle ${ }^{1}$, Michael A. Frölich ${ }^{2}$, Steve Tran ${ }^{2}$, Michael A. \\ Yassa $^{3}$, David Matthew White ${ }^{1}$, Abhishek Reddy ${ }^{1}$, and Adrienne Carol Lahti ${ }^{1}$ \\ ${ }^{1}$ Department of Psychiatry and Behavioral Neurobiology, University of Alabama at Birmingham \\ ${ }^{2}$ Department of Anesthesiology, University of Alabama at Birmingham \\ ${ }^{3}$ Department of Neurobiology and Behavior, Center for the Neurobiology of Learning and Memory, \\ Institute for Memory Impairments and Neurological Disorders, University of California, Irvine
}

\section{Abstract}

Background-Converging evidence from neuroimaging and post-mortem studies suggests that hippocampal subfields are differentially affected in schizophrenia. Recent studies report dentate gyrus dysfunction in chronic schizophrenia, but the underlying mechanisms remain to be elucidated. Here we sought examine if this deficit is already present in first episode psychosis, and if $\mathrm{N}$-methyl-d-aspartate (NMDA) receptor hypofunction, a putative central pathophysiological mechanism in schizophrenia, experimentally induced by ketamine, would result in a similar abnormality.

Methods-We applied a mnemonic discrimination task selectively taxing pattern separation in two experiments, (1) a group of 23 first episode psychosis patients and 23 matched healthy volunteers, and (2) a group of 19 healthy volunteers before and during a ketamine challenge $(0.27 \mathrm{mg} / \mathrm{kg}$ over 10 minutes, then $0.25 \mathrm{mg} / \mathrm{kg} /$ hour for 50 minutes, $0.01 \mathrm{ml} / \mathrm{s})$. We calculated response bias corrected pattern separation and recognition scores. We also examined the relationships between task performance and symptom severity as well as ketamine levels.

Results-We reported a deficit in pattern separation, but not recognition performance in first episode psychosis patients compared to healthy volunteers $(\mathrm{p}=.04)$ and in volunteers during ketamine the challenge compared to baseline $(\mathrm{p}=0.003)$. Exploratory analyses revealed no

Corresponding author: Adrienne C. Lahti, MD, Department of Psychiatry and Behavioral Neurobiology, University of Alabama at Birmingham, SC 501, $15303^{\text {rd }}$ Ave South, Birmingham, AL 35294-0017, Phone: (205) 996-6776, Fax: (205) 975-4879, alahti@uab.edu.

\section{FINANCIAL DISCLOSURES}

Dr. Lahti reports having received research funding from the National Institute of Mental Health (R01MH102951) and an investigator initiated grant from Janssen Pharmaceuticals. Dr. Kraguljac reports having received research funding from the National Institute of Mental Health (K23MH106683), the UAB Civitan International Research Center and UAB Center for Clinical and Translational Science. All other authors reported no biomedical financial interests or potential conflicts of interest.

Publisher's Disclaimer: This is a PDF file of an unedited manuscript that has been accepted for publication. As a service to our customers we are providing this early version of the manuscript. The manuscript will undergo copyediting, typesetting, and review of the resulting proof before it is published in its final citable form. Please note that during the production process errors may be discovered which could affect the content, and all legal disclaimers that apply to the journal pertain. 
correlation between task performance and RBANS total scores or positive symptoms in first episode psychosis patients, or with ketamine serum levels.

Conclusions-We observed a mnemonic discrimination deficit, but intact recognition in both datasets. Our findings suggest a tentative mechanistic link between dentate gyrus dysfunction in first episode psychosis and NMDA receptor hypofunction.

\section{Keywords}

Hippocampus; hippocampal subfields; CA3; pattern completion; pattern separation; glutamate

\section{INTRODUCTION}

The brain continuously simplifies and integrates sensory experiences in the context of prior memories, engaging in parallel competition between new, discrete memory formation and generalization across prior experiences (1). This process is thought to be supported by complementary computational operations, (1) pattern separation by which similar patterns of neuronal inputs are transformed into distinct neural representations $(2,3)$ and (2) pattern completion by which a full memory representation is evoked from a partial set of inputs (4). Theoretical models $(5,6)$ and growing empirical evidence (7-9) suggest that functionally distinct hippocampal subfields differentially and simultaneously contribute to these processes. The dentate gyrus is thought to operate as a competitive neuronal network performing pattern separation, delivering relatively orthogonal representation to the CA3 via sparse mossy fiber projections allowing episodic memories to be formed and stored within the CA3 network which then can be retrieved from a neural cue $(4,6)$. The balance of excitation and inhibition is likely to play an important role in this process (10). Dentate gyrus granule cells functionally innervate $\gamma$-aminobutyric acid (GABA) interneurons that are thought to heavily suppress dentate gyrus activity through feedback inhibition, which mediates sparsity and consequently also pattern separation by avoiding representational overlap (11). Furthermore, dentate gyrus N-methyl-d-aspartate (NMDA) receptors have been shown to mediate pattern separation in the hippocampal network in animal models (12).

Although the fundamental pathology underlying schizophrenia and its symptom domains remains elusive, abnormalities in the excitation/inhibition balance secondary to NMDA receptor hypofunction on GABAergic interneurons have been proposed as central mechanism $(13,14)$. Due to its neuronal composition, with a greater ratio of excitatory to inhibitory neurons than in the neocortex, the hippocampus may be especially vulnerable to shifts in the excitation/inhibition balance (15). In addition to reduced structural (16), functional $(17,18)$, and neurometabolic integrity $(19,20)$ of the hippocampus in medicated patients with schizophrenia, our group has reported excess hippocampal glutamate (21) and resting-state functional dysconnectivity $(22,23)$ in unmedicated patients. We suggested that NMDA receptor hypofunction may be a common pathological substrate, which we empirically supported in an experiment using ketamine (24), a non-competitive drug that preferentially blocks NMDA receptors on GABAergic interneurons (25-28) and is utilized as pharmacological model for schizophrenia (29-32). However, because of limitations in spatial resolution of conventional Magnetic Resonance Spectroscopy (MRS) and resting state functional MRI (fMRI), we were unable to make inferences on subfield-specific 
alterations, which is important as volumetric studies suggest differential alterations $(33,34)$, or even progression from selective to generalized involvement of hippocampal subfields in schizophrenia $(35,36)$.

Alternatively, cognitive tasks that differentially engage hippocampal subfields can help elucidate mechanisms of hippocampal pathology. Two studies utilizing a pattern separation and pattern completion task in patients with chronic schizophrenia found deficits in pattern separation, but not pattern completion $(37,38)$, suggesting dentate gyrus dysfunction. They concluded that this alteration likely contributes to memory deficits and psychotic symptoms (39), but failed to establish a relationship with positive symptom severity or memory performance. While a lack of statistical power in these preliminary experiments may explain findings, it is possible that a pattern separation deficit is the result of disease progression.

Here, we examined performance on mnemonic discrimination task selectively taxing pattern separation (for the sake of brevity referred to as pattern separation task hereafter) in (1) a group of first episode psychosis patients and matched healthy volunteers, and (2) a group of healthy volunteers with similar demographics before and during a pharmacological challenge with ketamine. We hypothesized that dentate gyrus dysfunction, as evidenced by impairments in pattern separation, is already present early in the illness, and that experimentally induced NMDA receptor hypofunction results in a similar deficit. In an exploratory fashion, we also examined possible relationships between task performance and positive symptoms as well as cognitive deficits.

\section{METHODS AND MATERIALS}

Patients were recruited from the First Episode Program at the University of Alabama at Birmingham. Healthy volunteers were recruited via flyers and advertisements. Studies were approved by the UAB Institutional Review Board, and written informed consent was obtained prior to enrolment (First episode psychosis patients had to be deemed competent to provide consent) (40).

Subjects were excluded if they had major neurological or medical conditions, a history of head trauma with loss of consciousness, substance use disorders (excluding nicotine) within six months of imaging, were pregnant or breastfeeding, or had MRI contraindications. Healthy volunteers with a history of an Axis I disorder or a psychotic disorder in a firstdegree family member were also excluded.

\section{Clinical Assessment}

The Brief Psychiatric Rating Scale (BPRS) (28) and its positive and negative subscales were used to assess symptom severity. Cognitive function was characterized using the Repeatable Battery for the Assessment of Neuropsychological Status (RBANS) (29).

\section{Task}

We used a pattern separation task involving two phases (41). During the incidental encoding phase subjects viewed 40 pictures of objects (presented for 2 seconds each followed by a 0.5 second inter-stimulus interval) on a computer screen and were asked to indicate with a key 
press whether the picture could be classified as an 'indoor' or an 'outdoor' item. To facilitate encoding, a five minute break was given prior to the second phase. During the recognition phase, subjects were shown 60 pictures for two seconds each, 20 were exactly the same as presented during encoding (targets), 20 were novel pictures not presented during encoding (foils), and 20 were pictures that are similar, but not exactly the same as shown during encoding (lures). Subjects were asked to indicate with a key press if they considered the picture to be 'old', 'similar', or 'new' in relation to those presented during encoding; they were given up to 2 seconds to respond (Figure, section A). Instructions were given according to the manual for the task. All subjects first completed a practical training run with one of three versions of the task (each using different sets of pictures) prior to completing the experiment with different versions of the task. The order of set presentation was randomized.

\section{Experiment 1}

We enrolled 23 first episode psychosis patients (schizophrenia $n=16$; schizoaffective disorder $n=7$ ), diagnoses were established by review of medical records, the Diagnostic Interview for Genetic Studies [DIGS (42)], and consensus of two board certified psychiatrists (ACL and NVK). Mean illness duration was 51.6+/-66.4 weeks, with median of 18 weeks. Twenty subjects were within the first two years of initial diagnosis, two were within the first three years, one was diagnosed 5.5 years prior to enrollment. Seventeen subjects were treated with risperidone, two with aripipazole, two with clozapine, and one with fluphenazine and risperidone; one subject had been stably off antipsychotic medications. Concomitant psychotropic medication was permissible (six subjects were prescribed benztropine, two sertraline, two fluoxetine, one citalopram, two trazodone, and one lithium). We also enrolled 23 healthy controls matched on sex, age, and parental socioeconomic status. After completing the training run, each subject completed one version of the task (different from the training set).

\section{Experiment 2}

We enrolled 19 healthy volunteers meeting eligibility criteria. A psychiatric assessment including the DIGS, physical exam, urine drug screen and, if applicable, pregnancy test was completed during the initial screen and before the ketamine infusion.

After completing a training run and one version of the task (different from the training set), subjects received an intravenous racemic ketamine challenge $(0.27 \mathrm{mg} / \mathrm{kg}$ bolus over 10 minutes, followed by a continuous infusion of $0.25 \mathrm{mg} / \mathrm{kg} /$ hour for 50 minutes) in the Clinical Research Unit. Ten milliliters of blood were collected immediately after completion of the bolus and 50 minutes after start of the challenge. Blood samples were centrifuged to obtain plasma and stored at $-40^{\circ} \mathrm{C}$. Ketamine plasma levels were assayed (Nathan Klein Institute, Orangeburg, NY) using a validated liquid chromatographic procedure, which included a liquid/liquid extraction with internal standard, followed by high-performance liquid chromatography/reversed phase column separation with UV detection. During the ketamine challenge, vital signs including heart rate, blood pressure, peripheral oxygen saturation, and respiratory rate were monitored by an anaesthesiology fellow under supervision of a board certified anaesthesiologist. Fifteen minutes after the continuous infusion started, subjects completed a third version of the task. Monitoring was continued 
for one hour after infusion completion. Prior to discharge into the care of an accompanying driver, subjects were medically cleared by the anaesthesiology fellow and psychiatrist. Two subjects withdrew prior to completing the task because of emesis.

\section{Statistical analyses}

Statistical analyses were performed with SPSS 23.0. Independent sample, two tailed t-tests and chi-square tests were used to investigate group differences in demographics and cognitive variables. Paired sample, two tailed t-test were conducted to assess change in BPRS scores between baseline and the ketamine infusion.

The response bias corrected pattern separation score (referred to as pattern separation hereafter) was calculated as $P$ ('similar'|lure) minus $P$ ('similar'|foil), and the response bias corrected recognition score (referred to as pattern recognition hereafter) was calculated as $P$ ('old'|target) minus $P$ ('old'|foil) (43). In an exploratory fashion, we also examined the relationships between pattern separation/pattern completion performance and symptom severity as well as ketamine plasma levels.

\section{RESULTS}

\section{Experiment 1}

Groups did not differ in gender, age, or parental occupation. Healthy volunteers scored significantly higher on RBANS compared to first episode psychosis patients (Table 1).

Healthy volunteers had significantly better pattern separation scores when compared to first episode psychosis patients $(\mathrm{t}=2.16 ; \mathrm{p}=.04)$, but pattern recognition performance did not differ between groups $(t=0.93 ; p=.36$; Figure, section $B)$. Further comparisons revealed that patients gave fewer SIMILAR responses to lures $(\mathrm{t}=2.53 ; \mathrm{p}=0.02)$ and OLD responses to targets $(\mathrm{t}=3.66 ; \mathrm{p}<0.01)$ and more NEW responses to lures $(\mathrm{t}=-3.83, \mathrm{p}<0.01)$ and targets $(\mathrm{t}=-2.86 ; \mathrm{p}<0.01)$, as well as SIMILAR responses to targets $(\mathrm{t}=-2.39 ; \mathrm{p}=0.02$; Table 2$)$. Exploratory analyses showed no correlations between RBANS scores and pattern separation or pattern completion scores, positive symptom severity and pattern separation scores were negatively correlated at trend level $(\mathrm{r}=-0.42 ; \mathrm{p}=.054)$.

\section{Experiment 2}

None of the subjects had baseline BPRS scores in the clinical range. As expected, BPRS total scores increased during the ketamine challenge (Table 1). Ketamine plasma levels were $81.95+/-32.44 \mathrm{ng} / \mathrm{ml}$ and $98.32+/-19.59 \mathrm{ng} / \mathrm{ml}$ immediately after completion of the bolus and 50 minutes after the start of the ketamine infusion, respectively.

During the ketamine challenge pattern separation $(\mathrm{t}=3.57 ; \mathrm{p}<.01)$, but not pattern recognition performance $(\mathrm{t}=-0.69 ; \mathrm{p}=.50)$ was significantly lower when compared to baseline (Figure C). Task performance during the saline and ketamine infusions were significantly correlated for pattern separation $(r=0.64 ; \mathrm{p}<.01)$, and correlated at trend level for pattern completion $(\mathrm{r}=0.48 ; \mathrm{p}=.054)$. Exploratory analyses showed no correlations between pattern separation and pattern recognition scores during the ketamine challenge and 
BPRS total, positive, and negative symptom scores, or ketamine plasma levels at either time point.

\section{DISCUSSION}

Here, we present results from two complementary experiments characterizing hippocampal subfield specific alterations with a pattern separation task in first episode psychosis patients and in a pharmacological model of schizophrenia $(32,33)$. As hypothesized, we observed a deficit in pattern separation, but not recognition implicating dentate gyrus involvement in the illness. Our findings extend prior studies reporting pattern separation abnormalities in chronic schizophrenia, and suggest a tentative mechanistic link between dentate gyrus dysfunction in first episode psychosis and NMDA receptor hypofunction.

While hippocampal volume loss is one of the most replicated findings in the schizophrenia literature (44), much less attention has been devoted to subfield specific alterations in this structurally and functionally heterogeneous area, in part because of the technical challenges in accurately delineating subfields in vivo. Neuroimaging studies report widespread volume loss across hippocampal subfields in chronic patients $(33,34)$, and a negative relationship between CA1 and CA2/3 volumes and positive symptom severity (45). Furthermore, a high resolution 7 Tesla MRI study investigating the dentate gyrus granule cell layer found a trendlevel decreased contrast in the right hippocampus in schizophrenia that was predictive of diagnosis (46). Examinations of hippocampal surface shape report only CA1 and CA2 deformities in first episode patients (47) and CA1 deformities chronic patients (48), but this method is not ideal to delineate subfields embedded deep in the hippocampal formation. A recent study reported evidence of progression from CA1 volume reduction in earlier stages of the illness (mean illness duration of 7 years), to a general involvement of hippocampal subfields in chronic patients (mean illness duration of 18 years), with the greatest volume decline in those with poor clinical outcomes (49). In contrast, Kawano and colleagues found an isolated dentate gyrus volume loss in first episode patients who had minimal prior exposure to antipsychotic medications. With illness progression, the authors noted increasing dentate gyrus atrophy along with volume deficits in the CA2/3 region, but not in CA1 (35). It is important to note that the cellular substrates and pathophysiological mechanisms underlying this putatively progressive structural deficit across subfields remain to be elucidated. Post-mortem evidence suggests no alteration in the total neuron number in any of the hippocampal subfields $(50,51)$, but rather a subtle decrease of parvalbuminpositive interneurons in the dentate gyrus and CA1 (52), and reduction of adult-born hippocampal granule cell neurons (53). The recent finding of reduced CA1 glutamic acid decarboxylase (GAD) immunoreactivity neutrophil density has been interpreted in support of hyperexcitation related to GABAergic impairment (54). Consistent with this, two functional investigations of hippocampal subfields identified selectively increased cerebral blood volumes in the CA1 in chronic patients $(55,56)$, an abnormality that also appears to be a marker of conversion to syndromal psychosis in prodromal patients (55), and likely driven by glutamatergic excess related to NMDA receptor hypofunction (57). In the CA3 but not CA1 subfield, an increase of GluN2B containing NMDA receptors along with other markers of synaptic plasticity in schizophrenia is reported (58). Taken together, findings are in support of an abnormal excitation inhibition balance related to NMDA receptor 
hypofunction that differentially, and possibly even progressively, adversely affects hippocampal subfields in schizophrenia.

Here, we report a deficit in pattern separation resulting from experimentally induced NMDA receptor blockade. Administration of subanesthetic doses of ketamine in healthy human subjects has shown to affect several cognitive domains including sustained attention (59), semantic memory (60), verbal memory (61), but not others such as working memory (62), recall accuracy (63), or reaction time (64). Animal models suggest intact hippocampal NMDA receptor function to be necessary for learning one-trial odor-place associations, but that recall can be performed without further involvement of NMDA receptors (65). Dentate gyrus granule cell specific GluN1NMDA receptor subunit knockout mice impair spatial, object-place association task performance, especially when places are close together and require pattern separation before storage in CA3 (12). This finding was later extended by Kannangara and colleagues who showed that global deletion of GluN2A, a subunit of the NMDA receptor, resulted in disrupted dentate gyrus signaling and compromised spatial pattern separation, likely related to a disturbance in synaptic plasticity (66). Similarly, lower GluN1, another NMDA receptor subunit, has been found to be decreased in the dentate gyrus, but not other hippocampal subregions (67). Consistent with this, computational models demonstrated that weak network inhibition increased errors in pattern separation (68) and absence of feedback inhibition resulted in an increased firing probability and decreased dentate gyrus pattern separation efficiency (69). Additionally, several in vivo neuroimaging studies in healthy subjects have linked dentate gyrus activity with pattern separation $(8,70)$, which is congruent with preclinical studies in rodents $(2,12,71)$.

It is noteworthy that we replicated findings from two prior studies examining pattern separation performance in patients with chronic schizophrenia $(37,38)$ in first episode psychosis patients, which suggests that dentate gyrus dysfunction may not merely be a result of disease progression. Impaired pattern separation in schizophrenia has been hypothesized to be associated with memory impairments and positive symptoms due to false memories with psychotic content $(37,39)$. We did not observe a correlation between pattern separation and RBANS scores. Neither did we find a significant correlation between positive symptom severity and pattern separation performance, which is consistent with a finding by Kim and Yassa who report no difference in the occurrence of false recollections across experiences where pattern separation does and does not occur (72). The lack of altered pattern recognition indices in either first episode psychosis patients or with a ketamine challenge also replicates data in chronic schizophrenia. Even though this dissociation of pattern separation and recognition abnormalities seems counterintuitive, a behavioral framework posits that if the dentate gyrus processes information as repetitive because of a disturbance in pattern separation, the CA3 and its connections to CA1 work to retrieve a stored representation based on the cue resulting in pattern completion (73), making it possible to have intact or even enhanced pattern completion performance.

Results of our experiments need to be interpreted in the context of several strengths and limitations. First episode psychosis patients and healthy volunteers in the first experiment were carefully matched on several key variables including age, gender, and parental socioeconomic status; demographics were comparable to those of healthy volunteers in the 
second experiment. We implemented a widely used task paradigm, calculated bias corrected outcome measures, and included a practice run to mitigate training effects. However, we did not parametrically alter the degree of inference of stimuli in the task, precluding us to make conclusions on the sensitivity of the task to detect changes in pattern separation (74). We also did not formally test visual discrimination, which has been shown to be associated with poor performance on a pattern separation task in patients with schizophrenia (37), it is therefore not possible to definitively attribute our findings to deficits in pattern separation as opposed to visual discrimination deficits. The increased tendency of identifying target and lure items as NEW in patients with first episode psychosis suggests failure to recognize previously seen items. As recommended by Martinelli and Shergill, future studies should include appropriate measures of recognition and visual discrimination performance to aid in interpretation of findings (37). First episode psychosis patients were treated with antipsychotic medication, which could have confounded outcomes. It will be important to include unmedicated patients in future studies to disentangle medication effects from intrinsic characteristics of the illness. We did not use a placebo control nor a crossover design in our ketamine experiment, which renders is possible that observed changes in task performance are entirely attributable to drug effects. It should also be noted that due to the systemic administration of ketamine, it is possible that other areas of the brain that are involved in pattern separation $(4,75)$ may contribute to the behavioral alterations observed with experimentally induced NMDA receptor hypofunction.

In summary, we present empirical evidence supporting a proposed mechanistic link between dentate gyrus dysfunction and NMDA receptor hypofunction, a key concept in this complex neuropsychiatric syndrome. Collectively, our findings add to the effort of bridging fundamental gaps in our understanding of neuropathological mechanisms of the illness and have potential clinical relevance. To date, no treatments for cognitive or negative symptoms are available. Targeting dentate gyrus dysfunction by modulating NMDA receptors may help alleviate symptom burden across symptom domains. A major challenge in this regard is that only systemic NMDA sensitive drugs are available, which fail to take into account that glutamatergic alterations may differ between subfields. Additionally, high resolution neuroimaging needs to confirm a direct conjunction between NMDA receptor hypofunction and dentate gyrus specific functional task activation deficits, and longitudinal studies need to establish utility and robustness of pattern separation as simple and inexpensive marker of NMDA receptor hypofunction in schizophrenia.

\section{Acknowledgments}

This work was supported by the National Institute of Mental Health (R01MH102951; Dr. Lahti; K23MH106683; Dr. Kraguljac), the UAB Civitan International Research Center and UAB Center for Clinical and Translational Science.

\section{References}

1. Johnston ST, Shtrahman M, Parylak S, Goncalves JT, Gage FH. Paradox of pattern separation and adult neurogenesis: A dual role for new neurons balancing memory resolution and robustness. Neurobiology of learning and memory. 2016; 129:60-68. [PubMed: 26549627]

2. Leutgeb JK, Leutgeb S, Moser MB, Moser EI. Pattern separation in the dentate gyrus and CA3 of the hippocampus. Science. 2007; 315:961-966. [PubMed: 17303747] 
3. Leutgeb S, Leutgeb JK. Pattern separation, pattern completion, and new neuronal codes within a continuous CA3 map. Learning \& memory. 2007; 14:745-757. [PubMed: 18007018]

4. Rolls ET. Pattern separation, completion, and categorisation in the hippocampus and neocortex. Neurobiology of learning and memory. 2016; 129:4-28. [PubMed: 26190832]

5. Treves A, Rolls ET. Computational constraints suggest the need for two distinct input systems to the hippocampal CA3 network. Hippocampus. 1992; 2:189-199. [PubMed: 1308182]

6. Rolls ET. The mechanisms for pattern completion and pattern separation in the hippocampus. Frontiers in systems neuroscience. 2013; 7:74. [PubMed: 24198767]

7. Neunuebel JP, Knierim JJ. CA3 retrieves coherent representations from degraded input: direct evidence for CA3 pattern completion and dentate gyrus pattern separation. Neuron. 2014; 81:416427. [PubMed: 24462102]

8. Bakker A, Kirwan CB, Miller M, Stark CE. Pattern separation in the human hippocampal CA3 and dentate gyrus. Science. 2008; 319:1640-1642. [PubMed: 18356518]

9. Lacy JW, Yassa MA, Stark SM, Muftuler LT, Stark CE. Distinct pattern separation related transfer functions in human CA3/dentate and CA1 revealed using high-resolution fMRI and variable mnemonic similarity. Learning \& memory. 2011; 18:15-18. [PubMed: 21164173]

10. English DF, Peyrache A, Stark E, Roux L, Vallentin D, Long MA, et al. Excitation and inhibition compete to control spiking during hippocampal ripples: intracellular study in behaving mice. The Journal of neuroscience: the official journal of the Society for Neuroscience. 2014; 34:1650916517. [PubMed: 25471587]

11. Nitz D, McNaughton B. Differential modulation of CA1 and dentate gyrus interneurons during exploration of novel environments. Journal of neurophysiology. 2004; 91:863-872. [PubMed: 14523073]

12. McHugh TJ, Jones MW, Quinn JJ, Balthasar N, Coppari R, Elmquist JK, et al. Dentate gyrus NMDA receptors mediate rapid pattern separation in the hippocampal network. Science. 2007; 317:94-99. [PubMed: 17556551]

13. Olney JW, Farber NB. Glutamate receptor dysfunction and schizophrenia. Archives of general psychiatry. 1995; 52:998-1007. [PubMed: 7492260]

14. Coyle JT, Tsai G. NMDA receptor function, neuroplasticity, and the pathophysiology of schizophrenia. International review of neurobiology. 2004; 59:491-515. [PubMed: 15006500]

15. Heckers S, Konradi C. GABAergic mechanisms of hippocampal hyperactivity in schizophrenia. Schizophrenia research. 2014

16. Reid MA, White DM, Kraguljac NV, Lahti AC. A combined diffusion tensor imaging and magnetic resonance spectroscopy study of patients with schizophrenia. Schizophrenia research. 2016; 170:341-350. [PubMed: 26718333]

17. Hutcheson NL, Reid MA, White DM, Kraguljac NV, Avsar KB, Bolding MS, et al. Multimodal analysis of the hippocampus in schizophrenia using proton magnetic resonance spectroscopy and functional magnetic resonance imaging. Schizophrenia research. 2012; 140:136-142. [PubMed: 22831772]

18. Hutcheson NL, Sreenivasan KR, Deshpande G, Reid MA, Hadley J, White DM, et al. Effective connectivity during episodic memory retrieval in schizophrenia participants before and after antipsychotic medication. Human brain mapping. 2015; 36:1442-1457. [PubMed: 25504918]

19. Kraguljac NV, Reid MA, White DM, den Hollander J, Lahti AC. Regional decoupling of N-acetylaspartate and glutamate in schizophrenia. Neuropsychopharmacology: official publication of the American College of Neuropsychopharmacology. 2012; 37:2635-2642. [PubMed: 22805603]

20. Kraguljac NV, Reid M, White D, Jones R, den Hollander J, Lowman D, et al. Neurometabolites in schizophrenia and bipolar disorder - a systematic review and meta-analysis. Psychiatry research. 2012; 203:111-125. [PubMed: 22981426]

21. Kraguljac NV, White DM, Reid MA, Lahti AC. Increased hippocampal glutamate and volumetric deficits in unmedicated patients with schizophrenia. JAMA psychiatry. 2013; 70:1294-1302. [PubMed: 24108440]

22. Kraguljac NV, White DM, Hadley J, Reid MA, Lahti AC. Hippocampal-parietal dysconnectivity and glutamate abnormalities in unmedicated patients with schizophrenia. Hippocampus. 2014; 24:1524-1532. [PubMed: 25045047] 
23. Kraguljac NV, White DM, Hadley N, Hadley JA, Ver Hoef L, Davis E, et al. Aberrant Hippocampal Connectivity in Unmedicated Patients With Schizophrenia and Effects of Antipsychotic Medication: A Longitudinal Resting State Functional MRI Study. Schizophrenia bulletin. 2016; 42:1046-1055. [PubMed: 26873890]

24. Kraguljac NV, Froelich MA, Tran S, White DM, Nichols N, Barton-McArdle A, et al. Ketamine modulates hippocampal neurochemistry and functional connectivity - a combined magnetic resonance spectroscopy and resting state fMRI study in healthy volunteers. Molecular psychiatry. 2016

25. Sapkota K, Mao Z, Synowicki P, Lieber D, Liu M, Ikezu T, et al. GluN2D N-Methyl-d-Aspartate Receptor Subunit Contribution to the Stimulation of Brain Activity and Gamma Oscillations by Ketamine: Implications for Schizophrenia. The Journal of pharmacology and experimental therapeutics. 2016; 356:702-711. [PubMed: 26675679]

26. Yamamoto T, Nakayama T, Yamaguchi J, Matsuzawa M, Mishina M, Ikeda K, et al. Role of the NMDA receptor GluN2D subunit in the expression of ketamine-induced behavioral sensitization and region-specific activation of neuronal nitric oxide synthase. Neuroscience letters. 2016; 610:48-53. [PubMed: 26520463]

27. von Engelhardt J, Bocklisch C, Tonges L, Herb A, Mishina M, Monyer H. GluN2D-containing NMDA receptors-mediate synaptic currents in hippocampal interneurons and pyramidal cells in juvenile mice. Frontiers in cellular neuroscience. 2015; 9:95. [PubMed: 25859181]

28. Intravenous Ketamine for the Treatment of Mental Health Disorders: A Review of Clinical Effectiveness and Guidelines. Ottawa (ON): 2014.

29. Lahti AC, Weiler MA, Tamara Michaelidis BA, Parwani A, Tamminga CA. Effects of ketamine in normal and schizophrenic volunteers. Neuropsychopharmacology: official publication of the American College of Neuropsychopharmacology. 2001; 25:455-467. [PubMed: 11557159]

30. Lahti AC, Koffel B, LaPorte D, Tamminga CA. Subanesthetic doses of ketamine stimulate psychosis in schizophrenia. Neuropsychopharmacology: official publication of the American College of Neuropsychopharmacology. 1995; 13:9-19. [PubMed: 8526975]

31. Lahti AC, Holcomb HH. Schizophrenia, VIII: pharmacologic models. The American journal of psychiatry. 2003; 160:2091. [PubMed: 14638574]

32. Anticevic A, Corlett PR, Cole MW, Savic A, Gancsos M, Tang Y, et al. N-methyl-D-aspartate receptor antagonist effects on prefrontal cortical connectivity better model early than chronic schizophrenia. Biological psychiatry. 2015; 77:569-580. [PubMed: 25281999]

33. Mathew I, Gardin TM, Tandon N, Eack S, Francis AN, Seidman LJ, et al. Medial temporal lobe structures and hippocampal subfields in psychotic disorders: findings from the BipolarSchizophrenia Network on Intermediate Phenotypes (B-SNIP) study. JAMA psychiatry. 2014; 71:769-777. [PubMed: 24828364]

34. Haukvik UK, Westlye LT, Morch-Johnsen L, Jorgensen KN, Lange EH, Dale AM, et al. In vivo hippocampal subfield volumes in schizophrenia and bipolar disorder. Biological psychiatry. 2015; 77:581-588. [PubMed: 25127742]

35. Kawano M, Sawada K, Shimodera S, Ogawa Y, Kariya S, Lang DJ, et al. Hippocampal subfield volumes in first episode and chronic schizophrenia. PloS one. 2015; 10:e0117785. [PubMed: 25658118]

36. Ho NF, Iglesias JE, Sum MY, Kuswanto CN, Sitoh YY, De Souza J, et al. Progression from selective to general involvement of hippocampal subfields in schizophrenia. Molecular psychiatry. 2016

37. Martinelli C, Shergill SS. Clarifying the role of pattern separation in schizophrenia: the role of recognition and visual discrimination deficits. Schizophrenia research. 2015; 166:328-333. [PubMed: 26117156]

38. Das T, Ivleva EI, Wagner AD, Stark CE, Tamminga CA. Loss of pattern separation performance in schizophrenia suggests dentate gyrus dysfunction. Schizophrenia research. 2014; 159:193-197. [PubMed: 25176349]

39. Tamminga CA. Psychosis is emerging as a learning and memory disorder. Neuropsychopharmacology: official publication of the American College of Neuropsychopharmacology. 2013; 38:247. [PubMed: 23147488] 
40. Carpenter WT Jr, Gold JM, Lahti AC, Queern CA, Conley RR, Bartko JJ, et al. Decisional capacity for informed consent in schizophrenia research. Archives of general psychiatry. 2000; 57:533-538. [PubMed: 10839330]

41. Stark SM, Yassa MA, Lacy JW, Stark CE. A task to assess behavioral pattern separation (BPS) in humans: Data from healthy aging and mild cognitive impairment. Neuropsychologia. 2013; 51:2442-2449. [PubMed: 23313292]

42. Nurnberger JI Jr, Blehar MC, Kaufmann CA, York-Cooler C, Simpson SG, Harkavy-Friedman J, Severe JB, et al. Diagnostic interview for genetic studies. Rationale, unique features, and training. NIMH Genetics Initiative. Archives of general psychiatry. 1994; 51:849-859. [PubMed: 7944874]

43. Yassa MA, Lacy JW, Stark SM, Albert MS, Gallagher M, Stark CE. Pattern separation deficits associated with increased hippocampal CA3 and dentate gyrus activity in nondemented older adults. Hippocampus. 2011; 21:968-979. [PubMed: 20865732]

44. Adriano F, Caltagirone C, Spalletta G. Hippocampal volume reduction in first-episode and chronic schizophrenia: a review and meta-analysis. The Neuroscientist: a review journal bringing neurobiology, neurology and psychiatry. 2012; 18:180-200.

45. Kuhn S, Musso F, Mobascher A, Warbrick T, Winterer G, Gallinat J. Hippocampal subfields predict positive symptoms in schizophrenia: first evidence from brain morphometry. Translational psychiatry. 2012; 2:e127. [PubMed: 22692142]

46. Kirov II, Hardy CJ, Matsuda K, Messinger J, Cankurtaran CZ, Warren M, et al. In vivo 7 Tesla imaging of the dentate granule cell layer in schizophrenia. Schizophrenia research. 2013; 147:362367. [PubMed: 23664589]

47. Narr KL, Thompson PM, Szeszko P, Robinson D, Jang S, Woods RP, et al. Regional specificity of hippocampal volume reductions in first-episode schizophrenia. Neuro Image. 2004; $21: 1563-$ 1575. [PubMed: 15050580]

48. Zierhut KC, Grassmann R, Kaufmann J, Steiner J, Bogerts B, Schiltz K. Hippocampal CA1 deformity is related to symptom severity and antipsychotic dosage in schizophrenia. Brain: a journal of neurology. 2013; 136:804-814. [PubMed: 23388407]

49. Ho BC, Alicata D, Ward J, Moser DJ, O'Leary DS, Arndt S, et al. Untreated initial psychosis: relation to cognitive deficits and brain morphology in first-episode schizophrenia. The American journal of psychiatry. 2003; 160:142-148. [PubMed: 12505813]

50. Walker MA, Highley JR, Esiri MM, McDonald B, Roberts HC, Evans SP, et al. Estimated neuronal populations and volumes of the hippocampus and its subfields in schizophrenia. The American journal of psychiatry. 2002; 159:821-828. [PubMed: 11986137]

51. Schmitt A, Steyskal C, Bernstein HG, Schneider-Axmann T, Parlapani E, Schaeffer EL, et al. Stereologic investigation of the posterior part of the hippocampus in schizophrenia. Acta neuropathologica. 2009; 117:395-407. [PubMed: 18777029]

52. Konradi C, Yang CK, Zimmerman EI, Lohmann KM, Gresch P, Pantazopoulos H, et al. Hippocampal interneurons are abnormal in schizophrenia. Schizophrenia research. 2011; 131:165173. [PubMed: 21745723]

53. Reif A, Fritzen S, Finger M, Strobel A, Lauer M, Schmitt A, et al. Neural stem cell proliferation is decreased in schizophrenia, but not in depression. Molecular psychiatry. 2006; 11:514-522. [PubMed: 16415915]

54. Steiner J, Brisch R, Schiltz K, Dobrowolny H, Mawrin C, Krzyzanowska M, et al. GABAergic system impairment in the hippocampus and superior temporal gyrus of patients with paranoid schizophrenia: A post-mortem study. Schizophrenia research. 2016

55. Schobel SA, Lewandowski NM, Corcoran CM, Moore H, Brown T, Malaspina D, et al. Differential targeting of the CA1 subfield of the hippocampal formation by schizophrenia and related psychotic disorders. Archives of general psychiatry. 2009; 66:938-946. [PubMed: 19736350]

56. Talati P, Rane S, Kose S, Blackford JU, Gore J, Donahue MJ, et al. Increased hippocampal CA1 cerebral blood volume in schizophrenia. Neuro Image Clinical. 2014; 5:359-364.

57. Schobel SA, Chaudhury NH, Khan UA, Paniaqua B, Styner MA, Asllani I, et al. Imaging patients with psychosis and a mouse model establishes a spreading pattern of hippocampal dysfunction and implicates glutamate as a driver. Neuron. 2013; 78:81-93. [PubMed: 23583108] 
58. Li W, Ghose S, Gleason K, Begovic A, Perez J, Bartko J, et al. Synaptic proteins in the hippocampus indicative of increased neuronal activity in CA3 in schizophrenia. The American journal of psychiatry. 2015; 172:373-382. [PubMed: 25585032]

59. Umbricht D, Schmid L, Koller R, Vollenweider FX, Hell D, Javitt DC. Ketamine-induced deficits in auditory and visual context-dependent processing in healthy volunteers: implications for models of cognitive deficits in schizophrenia. Archives of general psychiatry. 2000; 57:1139-1147. [PubMed: 11115327]

60. Stefanovic A, Brandner B, Klaassen E, Cregg R, Nagaratnam M, Bromley LM, et al. Acute and chronic effects of ketamine on semantic priming: modeling schizophrenia? Journal of clinical psychopharmacology. 2009; 29:124-133. [PubMed: 19512973]

61. Parwani A, Weiler MA, Blaxton TA, Warfel D, Hardin M, Frey K, et al. The effects of a subanesthetic dose of ketamine on verbal memory in normal volunteers. Psychopharmacology. 2005; 183:265-274. [PubMed: 16220331]

62. Rowland LM, Astur RS, Jung RE, Bustillo JR, Lauriello J, Yeo RA. Selective cognitive impairments associated with NMDA receptor blockade in humans. Neuropsychopharmacology: official publication of the American College of Neuropsychopharmacology. 2005; 30:633-639. [PubMed: 15647751]

63. LaPorte DJ, Blaxton TA, Michaelidis T, Robertson DU, Weiler MA, Tamminga CA, et al. Subtle effects of ketamine on memory when administered following stimulus presentation. Psychopharmacology. 2005; 180:385-390. [PubMed: 15719220]

64. Passie T, Karst M, Wiese B, Emrich HM, Schneider U. Effects of different subanesthetic doses of (S)-ketamine on neuropsychology, psychopathology, and state of consciousness in man. Neuropsychobiology. 2005; 51:226-233. [PubMed: 15897673]

65. Day M, Langston R, Morris RG. Glutamate-receptor-mediated encoding and retrieval of pairedassociate learning. Nature. 2003; 424:205-209. [PubMed: 12853960]

66. Kannangara TS, Eadie BD, Bostrom CA, Morch K, Brocardo PS, Christie BR. GluN2A-/- Mice Lack Bidirectional Synaptic Plasticity in the Dentate Gyrus and Perform Poorly on Spatial Pattern Separation Tasks. Cerebral cortex. 2015; 25:2102-2113. [PubMed: 24554729]

67. Stan AD, Ghose S, Zhao C, Hulsey K, Mihalakos P, Yanagi M, et al. Magnetic resonance spectroscopy and tissue protein concentrations together suggest lower glutamate signaling in dentate gyrus in schizophrenia. Molecular psychiatry. 2015; 20:433-439. [PubMed: 24912493]

68. Hanson JE, Madison DV. Imbalanced pattern completion vs. separation in cognitive disease: network simulations of synaptic pathologies predict a personalized therapeutics strategy. BMC neuroscience. 2010; 11:96. [PubMed: 20704756]

69. Faghihi F, Moustafa AA. A computational model of pattern separation efficiency in the dentate gyrus with implications in schizophrenia. Frontiers in systems neuroscience. 2015; 9:42. [PubMed: 25859189]

70. Berron D, Schutze H, Maass A, Cardenas-Blanco A, Kuijf HJ, Kumaran D, et al. Strong Evidence for Pattern Separation in Human Dentate Gyrus. The Journal of neuroscience: the official journal of the Society for Neuroscience. 2016; 36:7569-7579. [PubMed: 27445136]

71. Kesner RP, Kirk RA, Yu Z, Polansky C, Musso ND. Dentate gyrus supports slope recognition memory, shades of grey-context pattern separation and recognition memory, and CA3 supports pattern completion for object memory. Neurobiology of learning and memory. 2016; 129:29-37. [PubMed: 26318932]

72. Kim J, Yassa MA. Assessing recollection and familiarity of similar lures in a behavioral pattern separation task. Hippocampus. 2013; 23:287-294. [PubMed: 23401187]

73. Yassa MA, Stark SM, Bakker A, Albert MS, Gallagher M, Stark CE. High-resolution structural and functional MRI of hippocampal CA3 and dentate gyrus in patients with amnestic Mild Cognitive Impairment. NeuroImage. 2010; 51:1242-1252. [PubMed: 20338246]

74. Liu KY, Gould RL, Coulson MC, Ward EV, Howard RJ. Tests of pattern separation and pattern completion in humans-A systematic review. Hippocampus. 2016; 26:705-717. [PubMed: 26663362]

75. Pidgeon LM, Morcom AM. Cortical pattern separation and item-specific memory encoding. Neuropsychologia. 2016; 85:256-271. [PubMed: 27018483] 
A Mnemonic discrimination task

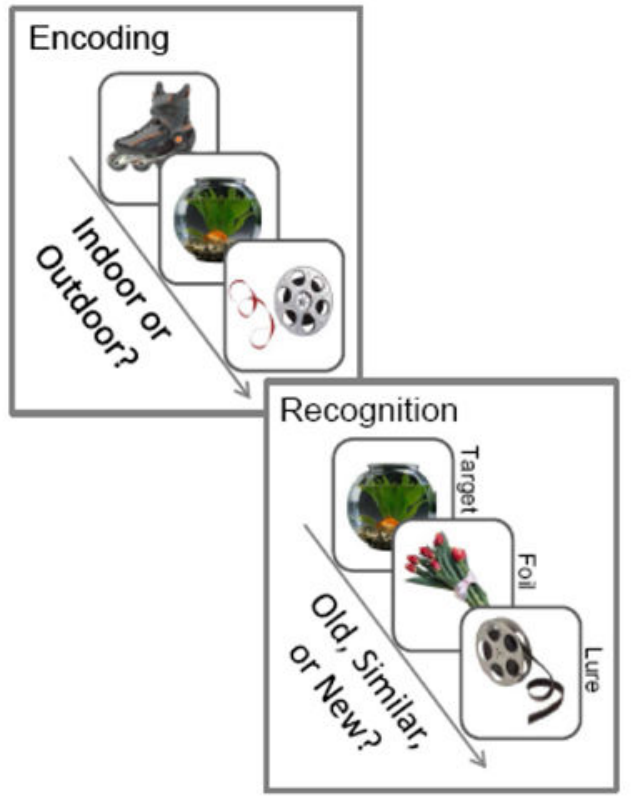

BPR = Old $\mid$ Target - Old $\mid$ Foil

BPS $=$ Similar|Lure - Similar|Foil
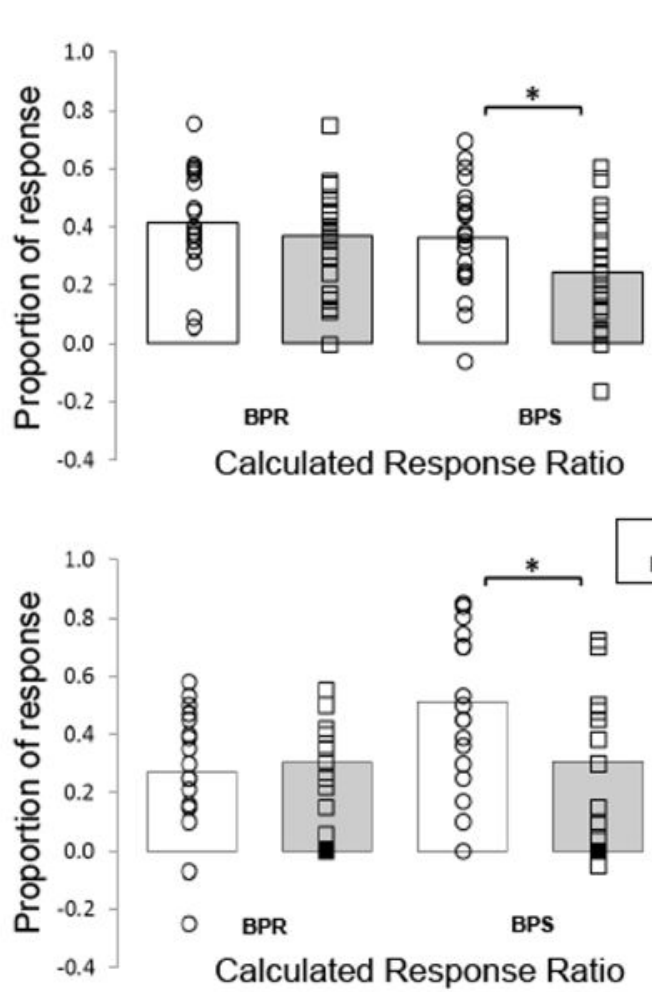

Figure.

Mnemonic Discrimination Task. A. The task had two phases, an incidental encoding phase, where subjects were asked to indicate with a key press whether the picture could be classified as an 'indoor' or an 'outdoor' item and a recognition phase where subjects were asked to indicate with a key press if they considered the picture to be 'old', 'similar', or 'new'. B. Task performance in a group of first episode psychosis (FEP) and healthy volunteers (HV); pattern separation scores were significantly lower in FEP compared to HV $(\mathrm{p}=.04)$. Dots represent individual measurements, and bars represent the overall group's performance. C. Task performance in HV at baseline and during a ketamine challenge; pattern separation scores were significantly lower during the ketamine challenge compared to baseline $(\mathrm{p}=.003)$. Dots represent individual measurements, and bars represent the overall group's performance. BPS: Bias corrected pattern separation score; BPR: Bias corrected pattern recognition score. 


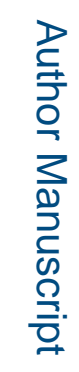

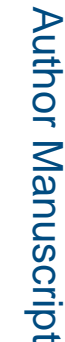

\begin{tabular}{|c|c|c|c|c|c|c|}
\hline \multirow{3}{*}{ 물 } & z & $\begin{array}{l}\hat{\sigma} \\
\dot{+} \\
\stackrel{0}{+} \\
\stackrel{0}{b} \\
\dot{\infty}\end{array}$ & $\begin{array}{l}\overparen{0} \\
\stackrel{0}{0} \\
\stackrel{0}{0} \\
\stackrel{\infty}{\infty}\end{array}$ & & 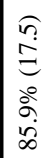 & 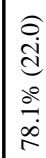 \\
\hline & 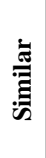 & 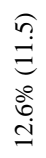 & $\begin{array}{l}\overparen{O} \\
\stackrel{0}{0} \\
\stackrel{0}{\circ} \\
\stackrel{0}{0}\end{array}$ & & 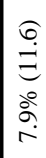 & 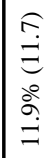 \\
\hline & $\overline{0}$ & 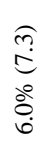 & $\begin{array}{l}\hat{\sigma} \\
\infty \\
\infty \\
\stackrel{\infty}{\infty} \\
\dot{\infty}\end{array}$ & & 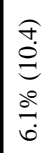 & 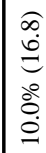 \\
\hline \multirow{3}{*}{ 总 } & ż & $\begin{array}{l}\widehat{\sigma} \\
\dot{b} \\
\frac{0}{2} \\
\dot{m}\end{array}$ & $\begin{array}{l}\text { } \\
\stackrel{\sigma}{\Xi} \\
\stackrel{0}{\sigma} \\
\stackrel{\sigma}{\sigma}\end{array}$ & & 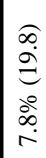 & 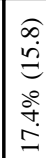 \\
\hline & 营 & $\begin{array}{l}\widehat{0} \\
\stackrel{\infty}{=} \\
\infty \\
\infty \\
\infty \\
\dot{0}\end{array}$ & $\begin{array}{l}\hat{\sigma} \\
\infty \\
\stackrel{\infty}{\sigma} \\
\stackrel{0}{m} \\
\ddot{n}\end{array}$ & & 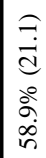 & 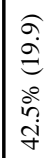 \\
\hline & $\overline{0}$ & 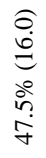 & 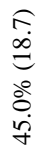 & & 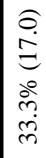 & 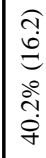 \\
\hline \multirow{3}{*}{ 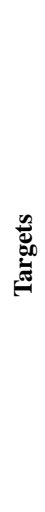 } & ż & 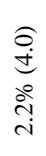 & $\begin{array}{l}\infty \\
\stackrel{\infty}{\Xi} \\
\stackrel{0}{0} \\
\stackrel{0}{=}\end{array}$ & & 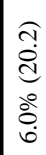 & $\begin{array}{l}\hat{\sigma} \\
\hat{\sigma} \\
o \\
\gamma \\
\sigma\end{array}$ \\
\hline & 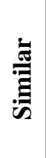 & 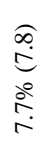 & 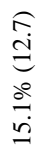 & & $\mid \begin{array}{c}\sigma \\
\infty \\
\infty \\
\stackrel{o}{\sigma} \\
\sigma\end{array}$ & 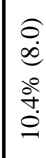 \\
\hline & $\overline{0}$ & 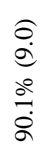 & 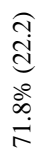 & & $\begin{array}{l}\text { ב. } \\
\dot{d} \\
0 \\
0 \\
i \\
\dot{0}\end{array}$ & 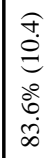 \\
\hline & 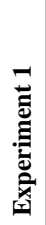 & 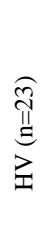 & 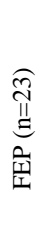 & 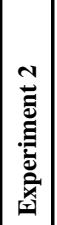 & 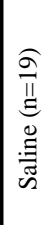 & 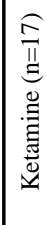 \\
\hline
\end{tabular}

Biol Psychiatry Cogn Neurosci Neuroimaging. Author manuscript; available in PMC 2019 March 01. 